\title{
Artificially induced group display and nesting behaviour in a reintroduced population of Caribbean Flamingo Phoenicopterus ruber ruber
}

\author{
C. E. O'CONNELL-RODWELL, N. ROJEK, T. C. RODWELL, \\ and P. W. SHANNON
}

\section{Summary}

We used artificial social stimulation (decoys, vocalization playbacks, and artificial nests) to initiate group displays in six (two females, four males) Caribbean Flamingos Phoenicopterus ruber ruber that had not successfully bred since their introduction to Guana Island, British Virgin Islands, in 1992. During a control period prior to the introduction of stimuli, flamingos exhibited no social displays or nest building activities. All flamingos were observed approaching the decoy area as a flock within four hrs of the decoys being introduced, and Head-Flagging displays were exhibited by two birds within the first $24 \mathrm{hrs}$. In a 12-hr watch conducted two-weeks post decoy introduction, there were significantly more group display behaviours, as well as nest-building, as compared with the control period and immediately after the introduction $(3.6 \%$ as compared with $0 \%$ and $0.35 \%$ ). Two individuals performed the majority of group displays (although at least one social display posture was observed for each bird) and three birds exhibited nest-building behaviour. Overall, individuals spent most of their time feeding and resting/sleeping $(>95 \%)$ during all observation periods. We show for the first time that decoys and vocalization playbacks could have a positive impact on breeding success in the wild by inducing group displays and nesting behaviours in this group of introduced flamingos. We suggest that social attraction techniques may be a useful tool to stimulate breeding in small captive and wild small populations of flamingos.

\section{Introduction}

Although their pre-Columbian distribution is not well known, Caribbean Flamingos Phoenicopterus ruber ruber historically occurred widely on islands and mainland shores in the Caribbean (Sprunt 1975). They were known to breed in the British Virgin Islands (BVI), particularly on Anegada Island where large numbers were recorded by European travellers in the 180os (Lazell 2001), but the population quickly declined as the birds were hunted for food, and by the 1950 s no resident flamingos were observed (Colli 1996). Although the species is not historically documented on Guana Island, BVI, the salt pond there could have provided foraging and nesting habitat.

In an attempt to re-establish Caribbean Flamingos in the BVI, eight birds from the Bermuda Zoo were brought to Guana Island, a wildlife sanctuary, in 1987 
(Lazell 2001, 2002). By 1992, four of these birds (all pinioned) had died and the remaining four free-flying birds had flown off the island. In 1992, eight more birds were released on Guana Island and 18 were reintroduced to Anegada Island (Lazell 2002). Courtship behaviour and nest building were observed in the Anegada population, but no chicks were observed until 1995 after four new birds (possibly the four from the original Guana Island introduction) had joined the Anegada flock. It has been reported that both populations appear not to be limited by food supply or excessive predation (Colli 1996), yet only the Anegada population has successfully bred, and has grown from 18 to 63 individuals (Lazell 2002). Recent data on salt pond nutrition cycling suggests that the Guana Island flamingos may be resource limited at certain times and this could be a limiting factor in population growth, though when food has been supplemented, mating did not occur (Jarecki pers. comm.).

The Guana population consists of six individuals, four males and two females that range in age from 9 to 21 years (Bermuda Zoo Caribbean Flamingo stud book). In the year following the 1992 release of birds, nest-building activity was observed in the centre of the salt pond, where an artificial island had been created. No egg-laying occurred and no social displays or breeding activity has been observed in subsequent years. The island was removed several years later.

Successful restoration programmes for colonially breeding birds require available food, reproductive success and low rates of predation. A threshold population size is also required, providing the necessary social stimulation to initiate group displays and subsequent copulation. Methods to re-establish colonial waterbird colonies and artificially stimulate breeding and nesting activities using "social attraction techniques" were first developed in the 1970s (Kress 1983, 1997). These techniques involve the use of decoys and vocalization playbacks to artificially simulate a large breeding colony. They are an effective management tool for encouraging the recolonization of a variety of extirpated seabird breeding colonies. The combination of decoys, mirrors, tape recordings of vocalizations, and in some cases, predator control, has led to successful restoration in many species (Parker et al. 2000, Kress 1997, Schubel 1993, Podolsky and Kress 1991, Podolsky and Kress 1989, Podolsky 1985). The use of plastic flamingos (painted white) alone has been used to attract wading birds to desired sites (Crozier and Gawlik 2003).

Successful reproduction in flamingos may require a minimum flock size (Stevens and Pickett, 1994). The lack of breeding activity in the Guana population may be due to an inadequate colony size to stimulate breeding behaviour. In captivity, a relationship has been found between behavioural stimulation from group displays and breeding success. Increasing the flock size at Zoo Atlanta from 17 birds to 21 birds played a role in increasing the frequency of display activity by $48 \%$ and synchronous group displays by $100 \%$, which resulted in a doubling in the frequency of mounts and copulation events (Stevens 1991). In captive flamingos, it has been shown that increases in group displays (which includes a vocalization component) stimulates breeding behaviour and increases reproductive success (Stevens 1991).

Studies of both captive and wild flamingos have indicated that artificial stimuli can enhance flamingo breeding. Large mirrors placed in the enclosure of captive Lesser Flamingos Phoeniconais minor resulted in an elevated rate of 
"marching displays" (a social group display) (Pickering and Duverge 1992). In France, the construction of an island and artificial nest mounds attracted wild flamingos, which had lost their nesting habitat nearby (Johnson 1976). In this case, the flamingos mated and produced young four years after the construction of the island. In our study, we tested whether the introduction of four artificial stimuli would induce group displays or any other reproductive behaviour in the Guana Island population of Caribbean Flamingos.

\section{Methods}

This study was conducted at the salt pond (approximately $300 \mathrm{~m}$ by $150 \mathrm{~m}$ ) on Guana Island, BVI, over a three-week period during July 2001. All flamingos $(n=6)$ were observed for a 12 -hr period over three days (3-5 July) during daylight hours (from 07 hoo to 19hoo), prior to the introduction of the artificial stimuli to obtain baseline data. All birds had numbered plastic leg bands allowing recognition of individuals. Observations were conducted from the west end of the pond, the furthest distance from the north-east end of the pond, where the birds were known to spend the majority of their time. The behaviour of each individual bird was recorded instantaneously every five min over the $12 \mathrm{hrs}$ using binoculars and a $15-45 \times$ spotting scope. Additionally, we recorded the same behaviour periods using a Sony Digital 8 video camera.

Normal behaviour was categorized as feeding, preening, wing-flapping, wing-stretching, walking, resting, or sleeping (Kahl 1975). Group or "ritualized" displays associated with breeding were categorized using established terms and descriptions (Kahl 1975, Studer-Thiersch 1975): Marching, Head-Flagging, WingSalute, Twist-Preen, Wing-Leg Stretch and Inverted Wing-Salute, False-Feeding, and Broken-Neck. Vocalizations associated with behaviours were also documented via video recorder. Courtship and nest-building behaviours were categorized as outlined in Shannon (2000). Courtship behaviour is not as discrete as group display behaviour, and involves a pairing off of a male and female, a female initiating copulation by stepping away from the group, the male following, and the female lowering her head into the water (False-Feeding) and spreading her wings. Nest-building behaviour was noted when a bird either stood on a nest, used its beak to fix a nest, or made contact with an artificial egg.

After the 12-hr baseline behavioural data were collected, four artificial stimuli were introduced to the site (decoys, nests, eggs and audio playbacks). Ten lifesized wooden flamingo decoys were placed near the shoreline of the south-east end of the pond to artificially increase the perceived population size, including seven decoys in Head-Flagging postures. Head-Flagging is the first in a series of group display postures that initiates subsequent group display postures (Kahl 1975, Studer-Thiersch 1975). A cluster of eight artificially constructed mud nests was built at the edge of the salt pond and three decoys in incubating postures and five artificial eggs were placed on various nests, an egg in each nest with the incubating decoys and two eggs on nests without decoy birds.

Head-Flagging calls were obtained from the Dallas Zoo and spliced together into a 30-min recording broadcast in a loop for 12 hours a day after the introduction of the decoys using a Sony water resistant CD player. A $12 \mathrm{~V}$ marine battery was used to power the CD player and was recharged once a week as needed. 
We observed the flamingos for two 12-hour sampling periods following the introduction of artificial stimuli. Two additional periods of observation were made: one within $24 \mathrm{hrs}$ after the introduction of the artificial stimuli (6-7 July) and a second two weeks later (16-18 July). For each observation period we calculated the percentage of observations of social/reproductive behaviours (group display or "ritualized" movements as listed above, plus courtship and nesting) for each individual bird and then calculated a mean for the time period. A univariate repeated measures ANOVA and Tukey's multiple comparison procedure were applied to compare the percentage of social/reproductive behaviour displayed by the birds among the three observation periods. This test was calculated in SAS, version 8.02 with observation period as a fixed factor and individual bird as a random factor and $\mu=0.05$.

\section{Results}

The occurrence of social/reproductive behaviour increased significantly following the introduction of artificial stimuli $\left(\mathrm{F}_{2,10}=5.80, P=0.0212\right)$, from o to $3.6 \%$. There was no difference between the observation periods before and immediately following the introduction of stimuli but a significant difference between both of these observation periods and the observation period two weeks later (Figure 1).

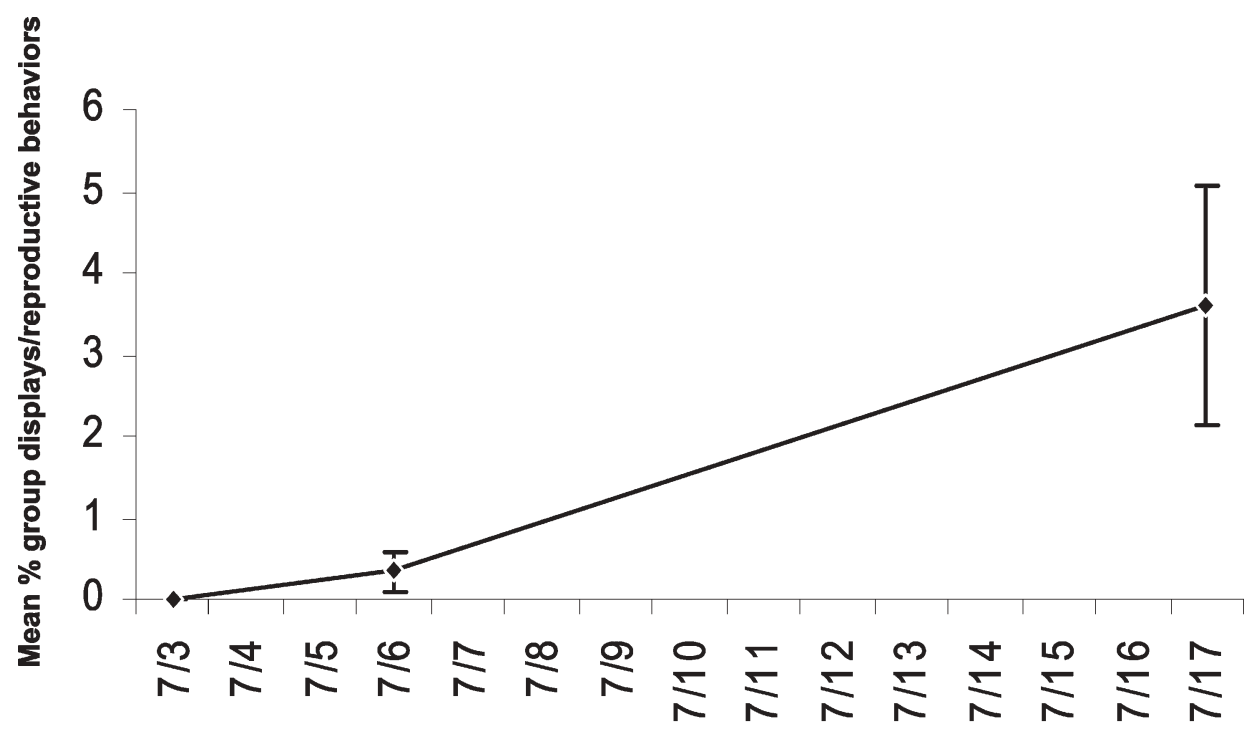

July 2001

Figure 1. Percentage occurrence of group display/reproductive behaviour 12 hours prior to, 12 hours after, and two weeks after introduction of artificial stimuli to a group of Caribbean Flamingos. Tukey multiple comparisons test indicates a significant change in behaviour two weeks after the introduction of artificial stimulation. Error bars represent standard error. (The non-parametric equivalent test was also significant.) 
Birds spent the majority of their time feeding during all observation periods (between 55 and 68\% of time), followed by sleeping or resting (between 15 and $27 \%$ of time), and preening (between 8 and $11 \%$ of time). Two weeks after stimuli introduction, $3.6 \%$ of time was spent in social/reproductive behaviours and these behaviours were exhibited between the hours of o7hoo-10hoo and 16hoo19hoo. Out of the $3.6 \%$ time spent in social/reproductive behaviours, $50 \%$ of the behaviours were Head-Flagging displays and $25 \%$ consisted of nest-building activities.

No social display or reproductive behaviour was exhibited during the $12 \mathrm{hr}$ observation period prior to the introduction of artificial stimuli. During the observation period immediately after stimuli introduction, three Head-Flagging social displays were recorded for two birds (0.003\% of total behaviours). Two weeks after the stimuli introduction, a total of 31 social/reproductive behavioural patterns were observed. During this last observation period, all but one individual exhibited social displays (including Head-Flagging, Wing-Salute, Twist-Preen, Wing-Leg Stretch and Inverted Wing-Salute) and three individuals engaged in nest-building activities. Nest-building behaviours included standing on the nests and using their beaks to scrape up the sides of the nests to make them taller, as well as removing debris from the nests with their beaks. Two individuals (one male and one female) displayed more and investigated the nests more than the others ( 13 and 10 recorded social/reproductive behaviour for these two birds, respectively, versus 2, 2 and 4 reproductive behaviours recorded for the others and one male bird did not exhibit any of these behaviours).

\section{Discussion}

Flamingos perform mass, mixed-sex group displays thought to play a role in ensuring synchronous nesting and/or facilitating pair formation (Pickering and Duverge 1992). The frequency of displays varies widely between individuals, unrelated to sex (Pickering and Duverge 1992), a phenomenon we also observed in our population, which may be an indication that certain members of the flock play a key role in instigating group displays. One male in particular played a key role in initiating displays. This has also been observed in other Caribbean Flamingo flocks (Shannon 2000).

Key studies have demonstrated the importance of male vocalizations in priming female hormones for reproduction. Lehrman and Freidman (1969) demonstrated that vocal stimulation done without visual cues caused a doubling in size of ovarian follicles in Ring Doves Streptopelia risoria. This phenomenon is also thought to be the case for Budgerigars Melopsittacus undulates (Ficken et al. 1960) and Canaries Serinus canaries (Warren and Hinde 1961). In Little Blue Penguin Eudyptula minor, it was further demonstrated that crested penguin Eudyptes sp. calls had no effect on their reproductive status, while male calls from their own species did (Waas 1988). In Royal Penguins Eudyptes schlegeli, the vocalizations from the colony as a whole facilitates sexual activities (Waas et al. 2000).

In flamingos, both sexes call during particular group displays, and Caribbean Flamingos have two distinct vocalizations associated with group displays, HeadFlagging and Wind-Salute calls (Kahl 1975). These vocalizations are most likely important to prime both sexes for reproduction. It is unclear what the relative 
role of the group display vocalizations and visual stimuli play in priming hormones in flamingos. The flamingos we studied oriented towards the decoys when preparing to display. The decoys were investigated on many occasions, and outside of display periods, at least three of the flamingos spent time amongst the decoys during nest building, resting and sleeping. The source of the vocalizations, on the other hand, was never investigated.

Field experimentation with social attraction techniques demonstrate the probable importance of the presence of decoys as a visual cue to land from a distance and in creating the appearance of a larger flock or colony. The relative importance of decoys versus vocalization playbacks is not yet completely understood. It would be interesting to have a site devoted to vocalization playbacks, a site devoted to decoys and a third site containing both sources of stimulation to determine which stimuli was more important, if not both.

Although the Anegada population has bred between April and June (Jarecki pers. comm.), Carribean Flamingos in captivity in North America usually breed between May-August (Reo and O'Gara 2001, Shannon 1996), some clutches occurring in April and September, but rarely in other months (Shannon 1996). Others report that breeding can occur at any time throughout the year in captivity, and they may breed twice in a year (Sedenko 2001). The Anegada population has previously had two clutches in a year, one in April and one in July (Jarecki pers. comm.). We expected, then, that the flamingo population on Guana Island may respond to breeding cues during the month of July. Although flamingos may not breed every year and breeding and nest-building may depend on rainfall and its effect on food supply, we expected that at least social group displays may be induced artificially at that time, regardless of the occurrence of any breeding behaviours. Although we observed nest-building behaviour in July, egg-laying may not have been possible due to the other environmental factors necessary for the flamingos to breed later than normal.

Having demonstrated that artificial stimuli induced group displays and nestbuilding in this group of Caribbean Flamingos, and caused a significant increase in these behaviours over time, we plan in the future to conduct these experiments prior to the breeding period (March-April) in order to maximize the potential of breeding. Typically, group displays are initiated one month prior to breeding, where the displays escalate throughout the month, culminating in pairing and mating in the following month (Shannon 2000). Additional studies are needed to determine nesting success, clutch size and population growth.

Our study indicates that the use of artificial stimuli could play an important role in flamingo reintroduction programmes, and perhaps even stimulate reproduction in wild populations of flamingos whose numbers have been drastically reduced. This technique could also be useful in captive breeding programs where other measures have failed to help stimulate breeding.

\section{Acknowledgements}

We would like to thank Steve Kress of the National Audubon Society for his support of the project and Jeanette Boylan of the Dallas Zoo for providing the Head-Flagging calls, and Byron Bodt of Bodt Decoys for making the decoys. We would also like to thank Lianna Jarecki, the director of the Marine Science 
Program on Guana Island for her enthusiastic support of this project, as well as Henry and Gloria Jarecki and Guana Island staff for assistance on the island. We thank James Lazell of The Conservation Agency for his input and the BVI National Parks Trust for providing data on the Anegada population. We also thank Dean Kildaw for his helpful comments on this manuscript. Funding for this project was provided by the Falconwood Corporation and Guana Island Marine Science Month.

\section{References}

Colli, C. (1996) Return of the flamingos. BVI Welcome Tourist Guide 25: 1-4.

Crozier, G. E. and Gawlik, D. E. (2003) The use of decoys as a research tool for attracting wading birds. J. Field. Orni. 74(1): 53-58.

Ficken, R. W., van Tienhoven, A., Ficken, M. S. and Sibley, F. C. (1960) Effects of visual and vocal stimuli on breeding in the budgerigar (Melopsittacus undulates). Anim. Behav. 8: 104-106.

Johnson, A. R. (1976) Flamingo breeding in the Camargue, 1974-1975. Terre et la Vie 30(4): 593-598.

Kahl, M. P. (1975) Ritualised displays. Pp. 142-149 in J. Kear and H. Duplaix-Hall, eds. Flamingos. Gloucester, U.K: Alan Sutton.

Kress, S. W. (1983) The use of decoys, sound recording and gull control for the re-establishment of a tern colony in Maine. Col. Waterbirds 6: 185-196.

Kress, S. W. (1997) Applying research for effective management: Case studies in seabird restoration. Pp. 141-154 in J. M. Marzluff and R. Sallabanks, eds. Avian conservation: research and management. Washington, D.C.: Island Press.

Lazell, J. (2001) Restoration of the Greater Flamingo (Phoenicopterus ruber) to Anegada, British Virgin Islands. El Pitirre 14(3).

Lazell, J. (2002) Restoring vertebrate animals in the British Virgin Islands. Ecol. Restoration 20(3): 179-185.

Lehrman, D. S. and Freidman, M. (1969) Auditory stimulation of ovarian activity in the ring dove (Streptopelia risoria). Anim. Behav. 17: 494-497.

Parker, M., Boyce, J., Young, R., Rojek, N., Hamilton, C., Slowik, V., Gellerman, H., Kress, S., Carter, H., Moore, G. and Cohen, L. J. (2000) Restoration of Common Murre colonies in central coastal California: Annual report 1999. Unpubl. report, U.S. Fish and Wildlife Service, San Francisco Bay National Wildlife Refuge Complex, Newark, California (prepared for the Apex Houston Trustee Council).

Pickering, S. P. C. and Duverge, L. (1992) The influence of visual stimuli provided by mirrors on the marching displays of lesser flamingos, Phoeniconais minor. Anim. Behav. 43: 1048-1050.

Podolsky, R. H. (1985) Colony formation and attraction of the Laysan Albatross and Leach's storm-petrel. Unpubl. Ph.D. dissertation, University of Michigan, Ann Arbor, Michigan.

Podolsky, R. H. and Kress, S. W. (1989) Factors affecting colony formation in Leach's storm-petrel. Auk 106: 332-336.

Podolsky, R. H. and Kress, S. W. (1991) Attraction of the endangered dark-rumped petrel to recorded vocalizations in the Galapagos Islands. Condor 94: 448-453.

Reo, J. and O'Gara, J. D. (2001) Color me pink: Five new flamingo chicks are thriving at Stone Zoo. http:/ / zoonewengland.com/main/pr/flamhatchoo.html.

Schubel, S. E. (1993) A Common Murre attraction project on a Maine island. Unpubl. report, National Audubon Society, Ithaca, New York.

Sedenko, M. (2001) American Flamingo. www.whozoo.org/Introg8/marisede/marinased. htm. 
Shannon, P. W. (2000) Social and reproductive relationships of captive Caribbean Flamingos. Pp. 173-178 in: Waterbirds 23 (Special Publication 1).

Shannon, P. W. (1996) North American Regional Studbook for Caribbean Flamingo (Phoenicopterus ruber ruber). 249 pages. Published by the author.

Sprunt, A. (1975) The Caribbean. Pp. 65-74 in J. Kear and H. Duplaix-Hall, eds. Flamingos. Gloucester, U.K.: Alan Sutton.

Stevens, E. F. (1991) Flamingo breeding: The role of group displays. Zoo Biol. 10: 53-64.

Stevens, E. F. and Pickett, C. (1994) Managing the social environments of flamingos for reproductive success. Zoo Biol. 13: 501-507.

Studer-Thiersch, A. (1975) Group display in Phoenicopterus. Pp. 150-158 in J. Kear and H. Duplaix-Hall, eds. Flamingos. Gloucester, U.K.: Alan Sutton.

Waas, J. R., Caufield, M., Colgan, P. W. and Boag, P. T. (2000) Colony sound facilitates sexual and agonistic activities in royal penguins. Anim. Behav. 60: 77-84.

Waas, J. R. (1988) Acoustic displays facilitate courtship in little blue penguins, Eudyptula minor. Anim. Behav. 36: 366-371.

Warren, R. P., and Hinde, R. A. (1961) Roles of the male and the nest-cup in controlling the reproduction of female canaries. Anim. Behav. 9: 54-67.

C. E. O'CONNELL-RODWELL

Center for Conservation Biology, 371 Serra Mall, Stanford University, Stanford, CA 943055020 , U.S.A. E-mail: ceoconnell@stanford.edu

N. ROJEK

U.S. Fish and Wildlife Service, 101 12th Avenue, Box 19, Room 110, Fairbanks, AK 99701, U.S.A.

T. C. RODWELL

Stanford Medical School, Stanford, CA 94305, U.S.A.

P. W. SHANNON

San Francisco Zoo, 1 Zoo Road, San Francisco, CA 94132-1098, U.S.A.

Received 17 October 2002; revision accepted 23 September 2003 